\title{
Predictive Parameters in Thyroid Cancer: The Mirror of an Endemic Country
}

\author{
Ahmet Kocakusak* \\ University of Health Sciences, Turkey
}

Submission: April 04, 2017; Published: June 02, 2017

*Corresponding author: Ahmet Kocakusak, General surgeon, General Surgery Clinic, Health Ministery Istanbul Haseki Education and Research Hospital, University of Health Sciences, Istanbul, Turkey, Tel: +905324484805; Email: ahmetkocakusak@yahoo.com

\section{Abstract}

It has been detected that the absence of thickening of isthmus and the solid nature of nodules, both had statistical significance in regard to predictivity of suspicious nodules. Although not statistically significant, there were differences in favour of malignancy between the groups when any of the parameters of solitary nodule, solid nature, loss of perinodular halo, hypoechoic nodule, and large nodule diameter were evaluated. In contrast to the expectancy; the number and diameter of nodules, in addition to gender were not found to be of significant predictive value in Turkey.

\section{Introduction}

The adult population in Turkey is 30 million. Scientifically, people with thyroid nodules have $6 \%$ cancer. As it is known that $40-50 \%$ of nodules are found in western societies, it is known that thyroid cancer is present in approximately 900.000 people in a country of 70 million according to the existence of the thyroid gland which contains at least one nodule in an endemic goiter country as Turkey. However, very few of the patients are diagnosed, and for the most part, their lives continue without being diagnosed as being cancerous or because the cancer has not progressed. Since small nodules can also develop cancer, nodule dimensions are no longer important. Thirteen percent of thyroid carcinomas are reported in autopsy series in the present country. In fact, in the autopsy series, Harach and colleagues found that $36(35.6 \%)$ papillary thyroid microcarcinomas were found in 101 consecutive autopsies [1]. Occasionally, incidental thyroid cancer can disguise a quiet or even dangerous course of thyroid cancer. In recent years, thyroid diseases that require surgery are now being treated with lobectomy or total thyroidectomy. Today, it is known that multinodular goitre is less risky of cancer than single nodule containing thyroid glands. Distribution of iodine tablets in endemic areas prevents cancer. When goitrogens and carcinogenic factors are combined, the conversion of thyroid disease to cancer in every region is different from each other in our country. It is not appropriate for us to copy the algorithm of the approach to the thyroid nodule from countries without endemic disease in the same way. Algorythms in countries with thyroid nodules in their population with an incidence of $5-10 \%$ are unfortunately inferred as references to the Turkish population in whom $65 \%$ of thyroid glands have nodules. For example, in our country, which has lived with intense effects of the Chernobyl nuclear disaster with close proximity, it is reported that the cancer rate in the hyperactive nodule is much higher than the world average. According to us; selection of appropriate predictive parameters and logistic regression analysis can be used to develop a local scoring system to detect when the likelihood of malignancy of the suspicious thyroid nodule is suspected at the outpatient clinic. So, the general surgeon will not learn from the pathology report after the surgery that the patient who is operated on has actually cancer and will be able to choose appropriate surgery previously. In order to be able to create a model of the country in the scoring system; thyroid cancer patients who underwent surgery in our General Surgery Clinic were evaluated in comparison with a control group, in regard to various parameters.

\section{Patients and Methods}

The files' informations, in addition to surgery and pathology reports of 50 consecutive patients who had been operated on for thyroid carcinoma between 2004 and 2011 were evaluated retrospectively in Haseki Education and Research Teaching Hospital's General Surgery Clinic of Health Sciences University. The study group constituted of 50 consecutive patients with thyroid cancer. The control group was 50 consecutive patients who did not have hyperthyroidism and underwent total thyroidectomy in the same period. Parameters used for group comparison; were age, gender, nodule diameter, number of 
nodules, suspicious finding on scintigraphy, hormone status, blood group, suspicion in FNAB, and ultrasonography.

Presence of nodules within nodules, ultrasonographic nature of nodule (cystic, solid, mixed), abnormality of isthmus thickness on ultrasonography, filling of the nodule almost totally the lobe in ultrasonography, presence of microcalcification on ultrasonography, presence of hypoechoic nodule on ultrasonography, loss of halo around the nodule on ultrasonography, Intra-nodal vascularization in Doppler ultrasonography were studied. Apart from this; the data containing valuable information which is not used in comparison were also considered.

We evaluated the distribution of cancer types we encountered. Minimal invasive thyroid cancer was deemed as a tumor with diameter $\leq 1 \mathrm{~cm}$ with no lymphovascular and capsule invasion. Tumor diameter was assessed. If there is even one of the suspicious findings in the ultrasonography; ultrasonography was generally considered as a predictive decision-making factor in the statistical examination. Positive ultrasonography parameters that provide predisposition were the nodule nature (cystic, solid, mixed), presence of microcalcification, presence of hypoechoic nodule, loss of halo around the nodule, and increased intranodular vascularization. Other ultrasonographic parameters were the isthmus thickness, the presence of congromerulated nodules (nodules within nodules), and filling of the nodule almost the total lobe. The existence of at least one of the former ultrasonographic parameters other than the ultrasonographic parameters we have added has fulfilled our suspicious findings on ultrasonography.

\section{Statistical method}

Mean, standard deviation, ratio and frequency values were used in the descriptive statistics of the data. The distribution of the data was tested with Kolmogorov-Smirnov. Parametric data were tested by t test. The chi-square test was used to analyze proportional data, and the fischer exact test was used when chisquare test not met the criteria. Risk analysis was carried out for the effects of variables on cancer formation. SPSS 19.0 program was used for analysis.

\section{Results}

There was no significant difference $(p>0.05)$ between sex ratios of patients with thyroid cancer (female: 39/78\%- male: $11 / 22 \%$ ) patients without cancer (female: $42 / 84 \%$ - male: $8 / 16 \%)$. There was no significant difference $(p>0.05)$ among the age groups of patients with thyroid cancer $(50.5 \pm 14.4)$ and those without cancer $(48.8 \pm 12.5)$.

In the patient group with thyroid cancer, the solid naturality rate was statistically significant $(\mathrm{p}=0.004<0.05)$.

There was no significant difference in the number of nodules, nodule diameter, hormone status, IIAB, congromerulated nodules, total cholesterol values, microcalcification, halo loss, nodule almost totally filling the lobe, hypoechoic nodule ratios $(p>0.05)$ in patients with and without thyroid cancer.Thick isthmus thickness $(76 \%)$ was significantly high $(\mathrm{p}=0.021<0.05)$ in the non-cancer group when compared to thyroid cancer group (54\%). In those with thyroid cancer the likelihood of thin to normal thickness was 2.698 (range 1,148-6,341) times more. Sensitivity of determining benign cases was $78 \%$ when the nodule filled the lobe almost totally.

\section{Discussion}

The rate of cancer in multinodular goiter in the present study was not reduced which was in accordance with the literature. The incidence of thyroid cancer in our male and female patients was similar, which was not consistent with the literature [1]. However, our male and female patient ratio wass similar to the literature. The cause of this contradiction is not understood and thyroid cancer did not choose sex according to the present study.

In the case of goitre patients, each lobe should be regarded as a separate thyroid organs and in some patients lobetomy+isthmectomy should be preferred instead of total thyroidectomy [2]. The inadequacy of ultrasonography reports was noteworthy in our patients. Suspicious nodules can have hypoechogenicity, irregular borders, halo loss, and solid natures. When ultrasonography is not performed well, this can lead to the wrong choice of treatment. Even if ultrasonography is done with care, there are occult points in this subject. For example; although egg shell calcification, which is considered as macrocalcification, is now being interpreted in favor of benign disease, there are also authors who talk about the risk of cancer up to $40 \%$ in them [3-6]. For us, the USG is as important as the FNAB due to the improved USG equipments available today. Using the color doppler USG to evaluate the blood flow of the nodule has been suggested to be useful in determining malignancy risk. While the blood circulation at the periphery of the nodule is benign, the blood at the center of the nodule suggests a malignant nodule. Nodules according to the characteristics of blood circulation can be classified as; no circulation at all, perinodular blood flow, intranodular blood flow, and complete blood flow to the nodule. It has been suggested that intranodal type of blood flow increases the risk of malignancy in the nodule [2-4].

It has been accepted that $14-22 \%$ of cold nodules and $1 \%$ of hot nodules are malignant, although scintigraphy has gradually lost its importance nowadays. There are known problems in determining whether the nodules are cold or hot because the thyroid planes are projected on top of each other with only twodimensional image presentation, and even when the nodule remains behind a larger nodule where no vision is visible. Technetium-99 pertechnetate or radioactive iodine is used for thyroid scintigraphy. Most benign nodules and malignant tumors, all take less radioisotope than normal thyroid tissue [2]. According to our results; microinvasive papillary cancer was a separate problem. Many microinvasive papillary cancers are being skipped, but researchers claim that this cancer type 
is not progressing, so the patient's thyroid cancer will not cause a problem. As a result, microinvasive papillary cancer is not considered even to be malignant [7-11]. According to the results of our study, microinvasive papillary cancer was detected in 26 patients, but 12 of them were found incidentally in goiters with no cancer suspicion preoperatively. In our study, these patients were included in the cancer group since these mostly skipped patients although detected incidentally, they were treated as aggressive as other cancers. In fact, only $10 \%$ of all thyroid cancer patients in general are lost for a long time due to thyroid cancer [2].

It has been proven that more than one foci in one lobe, and even bilateral papillary thyroid cancer are not intraglandular metastasis of each other, since each of them come from separate cancer cell clones. Individuals with chromosomal breaks or with distinct environmental factors may develop separate synchronous cancers at several focuses, but these usually do not progress [8]. The results of frozen examinations were hardly ever applied in our series and were misleading when applied as also reported in the literature [9]. The normal upper limit of thyroid isthmus thickness is $5 \mathrm{~mm}$, so this value was taken as the upper limit of the thickness of the isthmus for our parameters.

We believe that total thyroidectomy does not cause more complications than other methods of thyroid surgeries. Similar experienced centers like our clinic do not increase the rate of harm to vocal cords due to recurrent nerve damage $[2,12]$. We think that the endoscopic examination

by a specialist in eye nose throat unit before and after surgery is useful for this purpose. Total thyroidectomy or completion thyroidectomy did not result in any cord paralysis in our series but transient parathyroid damage was more common than it has been reported in the literature, a result which could be attributed to higher incidence of hungry bone syndrome in Turkey. According to us, even minimally invasive thyroidectomy will not be performed when microinvasive cancer is detected in the near future. Considering many factors, although invasive thyroid cancer and microinvasive thyroid cancer are completely different diseases and different from each other, they are all treated in the same way due to lack of evidence unfortunately.

\section{Conclusion}

It has been detected that the absence of thickening of isthmus and the solid nature of nodules, both had statistical significance in regard to predictivity of suspicious nodules. Although not statistically significant, there were differences between the groups when any of the parameters of solitary nodule, solid nature, loss of perinodular halo, hypoechoic nodule, and large nodule diameter were evaluated. In contrast to the expectancy; the number and diameter of nodules, in addition to gender were not found to be of predictive value. Papillary cancer replaced the place of follicular cancer in Turkey. If we review the data of our patients with microinvasive cancer retrospectively, we can speculate that most of these patients would not be operated on if they had been evaluated with internationally accepted parameters, and nevertheless would not have a life-long problem with thyroid cancer, too. It has been observed that the statistically significant USG findings for benign thyroid disease were a nodule almost totally filling a complete lobe, the presence of congromerulated nodules, and the increased thickness of the isthmus. Although they did not take part in the study group, 2 of the 6 patients $(1 / 3)$ had residual cancer following completion thyroidectomies which was a result consistent with the related literature $[2,13]$.

\section{References}

1. Harach HR, Franssila KO, Wasenius VM (1985) Occult papillary carcinoma of the thyroid. A "normal" finding in Finland. A systematic autopsy study. Cancer 56(3): 531-538.

2. Lin YS, Wu HY, Yu MC, Hsu CC, Chao TC (2016) Patient outcomes following surgical management of multinodular goiter: Does multinodularity increase the risk of thyroid malignancy? Medicine (Baltimore) 95(28): e4194.

3. Cooper DS, Anton B (2016) The Decade in Clinical Thyroid Disease: An Analysis of Published Literature. Thyroid 26(8): 993-1003.

4. De Napoli L, Bakkar S, Ambrosini CE, Materazzi G, Proietti A, et al. (2016) Indeterminate Single Thyroid Nodule: Synergistic Impact of Mutational Markers and Sonographic Features in Triaging Patients to Appropriate Surgery. Thyroid 26(3): 390-394.

5. Rago T, Fiore E, Scutari M, Santini F, Di Coscio G, et al. (2010) Male sex, single nodularity, and young age are associated with the risk of finding a papillary thyroid cancer on fine-needle aspiration cytology in a large series of patients with nodular thyroid disease. Eur J Endocrinol 162(4): 763-770.

6. Rago T, Vitti P (2009) Potential value of elastosonography in the diagnosis of malignancy in thyroid nodules. Q J Nucl Med Mol Imaging 53(5): 455-464.

7. Hong Y, Liu X, Li Z, Zhang X, Chen M, et al. (2009) Real-time ultrasound elastography in the differential diagnosis of benign and malignant thyroid nodules. J Ultrasound Med 28(7): 861-867.

8. Conzo G, Troncone G, Docimo G, Pizza A, Sciascia V, et al. (2013) Cytologically undetermined thyroid's follicular lesions: surgical procedures and histological outcome in 472 cases. Ann Ital Chir 84(3): 251-256.

9. Selek A, Cetinarslan B, Tarkun I, Canturk Z, Ustuner B, et al. (2017) Thyroid autoimmunity: is really associated with papillary thyroid carcinoma? Eur Arch Otorhinolaryngol 274(3): 16771681.

10. Estebe S, Montenat C, Tremoureux A, Rousseau C, Bouilloud F, et al. (2017) Limitation of intraoperative frozen section during thyroid surgery. Eur Arch Otorhinolaryngol 274(3): 1671-1676.

11. González-Sánchez-Migallón E, Flores-Pastor B, Pérez-Guarinos CV, Miguel-Perelló J, Chaves-Benito A, et al. (2016) Incidental versus non incidental thyroid carcinoma: Clinical presentation, surgical management and prognosis. Endocrinol Nutr 63(9): 475-481.

12. Kaliszewski K, Wojtczak B, Strutyńska-Karpińska M, Łukieńczuk T, Forkasiewicz Z, et al. (2016) Incidental and nonincidental thyroid microcarcinoma. Oncol Lett 12(1): 734-740.

13. Sharma SD, Kumar G, Guner K, Kaddour H (2016) Hyperthyroidism in patients with thyroid cancer. Ear Nose Throat J 95(6): 236-239. 
This work is licensed under Creative Commons Attribution 4.0 Licens

DOI: 10.19080/JETR.2017.02.555582
Your next submission with Juniper Publishers will reach you the below assets

- Quality Editorial service

- Swift Peer Review

- Reprints availability

- E-prints Service

- Manuscript Podcast for convenient understanding

- Global attainment for your research

- Manuscript accessibility in different formats

( Pdf, E-pub, Full Text, Audio)

- Unceasing customer service

Track the below URL for one-step submission https://juniperpublishers.com/online-submission.php 